\title{
Did 'generic' London image breach copyright?
}

\author{
Catherine Lee
}

Journal of Direct, Data and Digital Marketing Practice (2012) 13, 372-375. doi:10.1057/dddmp.2012.7

Topic: Photographs

Who: Temple Island Collections (TIC) Ltd, New English Teas (NET)

Ltd and Nicholas Houghton

Where: The Patents County Court (HHJ Birss QC), London

When: January 2012

Law stated as at: 1 February 2012

Background

Originality
Judgement was recently handed down in the controversial London Buses Case.

Temple Island Collections (TIC), who produces souvenirs of London, claimed to be the owner of the copyright that subsisted in Image 1 . Image 1 was created by Mr Fielder after manipulating a photo that he had taken with Photoshop software and was first published in February 2006.

New English Teas (NET) wished to use Image 2 on its tea-related products. Image 2 was created by Mr Houghton and Sphere Design after the combination and manipulation of four photographs taken by Mr Hougton. Significantly, prior to the proceedings in question, TIC had alleged that NET had infringed copyright in Image 1 by the use of the so-called 'First Allegedly Infringing Work'. These proceedings were settled on the basis that NET agreed to withdraw the 'First Allegedly Infringing Work'.

To view the images concerned, please visit http://www.bailii.org/ew/ cases/EWPCC/2012/1.html.

\section{Did NET's use of Image 2 infringe TIC's copyright in Image 1?}

Judge Birss found (at [51]) that Image 1 was original and thus capable of copyright protection. He explained that it is the result of Mr Fielder's 'own intellectual creation both in terms of his choices relating to the basic photograph itself: the precise motif, angle of shot, light and shade, illumination, and exposure and also in terms of his work after the photograph was taken to manipulate the image to satisfy his own visual aesthetic sense. The fact that it is a picture combining some iconic symbols of London does not mean the work is not an original work in which copyright subsists'. 
For Judge Birss, the particular elements worthy of attention in Image 1 were (at [52]):

(i) Its composition: not just Big Ben but a substantial frontage of the Houses of Parliament and the arches of Westminster Bridge. The bus is on the central left side near a lamppost. It is framed by building behind it. People can be seen on the bridge and some are in front of the bus, but they are not prominent. Portcullis House is visible, as well as the river itself.

(ii) The visual contrasts: one between the bright red bus and the monochrome background, and the other between the blank white sky and the rest of the photograph.

\section{Infringement}

\section{Had Image 1 been copied?}

\section{What features had been copied?}

Under Sections 16 and 17 of the Copyright Designs and Patents Act 1988, copyright is infringed by reproducing the whole or a substantial part of a work in a material form. 'Substantial part' in this instance is a matter of quality not quantity. According to the House of Lords decision in Designer Guild Ltd v Russell Williams (Textiles) Ltd, Judge Birss had to decide: (a) whether there had been copying; (b) if so, which features had been copied; and (c) whether the copying represented a substantial part of the original work.

Judge Birss found (at [55]) that Image 1 had been copied by Mr Houghton. Given the 'obvious similarities' between the two images, for Judge Birss the onus fell to NET to argue that there had not been any copying. NET was unable to do so for two reasons.

First, Mr Houghton had seen Image 1 (as demonstrated by the earlier proceedings). Second, Mr Houghton did not suggest that he had seen any of the other similar works depicting a red Routemaster, Westminster Bridge, Big Ben and the Houses of Parliament that NET had submitted in evidence before seeing Mr Fielder's Image 1.

Judge Birss addressed (at [58]) features of composition and visual contrast. In terms of composition:

(i) Elements of the composition of the claimant's work, which have not been taken, are the prominent arches of the bridge and the river, the steps in the foreground and the prominent lamppost. The angle to the vertical is somewhat different since the road can be seen with the bus sitting on it in the defendants' image, whereas from the angle of the claimant's picture a balustrade obscures the road. The angle presented by the facade of the Houses of Parliament is different: in the defendants' image, the perspective of the facade falls away more sharply, whereas in the claimant's image there is much less perspective. The bus is on the central right side of the image, touching Big Ben it is not left of centre as in the claimant's picture. The defendants' bus is bigger and presents a slightly different angle to the viewer. There are no people in front of the defendants' bus.

(ii) Although the images undoubtedly differ in their composition, elements of the overall composition of the claimant's image have been reproduced. The bus is a Routemaster, driving from right to 


\section{Were these copied features a substantial part of Image 1?}

left with Big Ben on the right of the bus. The riverside facade of the Houses of Parliament is part of the image. The bus is on Westminster Bridge (although in a different place) in both images. This is obvious in the claimant's image and can be seen from the presence of the balustrade on the left in the defendants' image. There are some people visible but they are small (and in different places). There is no other obvious traffic.

The edge of Portcullis house is visible on the right. Running from top to bottom, there is a substantial amount of sky in the picture (although more in the claimant's) and the top of the bus is roughly the same height as the facade of the Houses of Parliament.

In terms of visual contrast:

(i) The element of bright red bus against a black and white background has been reproduced.

(ii) The element of the blank white sky, which creates a strong sky line, has been reproduced. A small point arose that the image produced by Sphere actually has no sky at all, and thus it takes on the background of the box it is placed on. Nothing turns on that since in use it is placed on a white (or very pale grey) tin.

This was 'not an easy question', but Judge Birss found (at [63]) that Image 2 did reproduce a substantial part of Image 1 because they still include the key combination of 'visual contrast features with the basic composition of the scene itself'. Two factors influenced Judge Birss in arriving at this decision: the nature of Mr Fielder's image (at [66]) (its appearance being the product of deliberate choices and deliberate manipulations) and the collection of other similar works relied upon by NET (at [67]) (it counting against NET because 'the collection served to emphasize how different ostensibly independent expressions of the same idea actually look').

It is a fundamental principle of copyright law that copyright does not protect an idea of itself, but the expression of that idea as a work (eg literary, dramatic, musical or artistic works). For example, the idea of writing a biography of the famous English footballer David Beckham is not protected by copyright, and nor is information about his life; however, a particular literary text describing his life is protected. Applying the same approach to photographs, the idea of taking a photo of Nelson's Column in Trafalgar Square in London is not protected by copyright. This is because there is an infinite number of ways that one could express that idea, such as taking the photograph standing on the steps of the National Gallery London or looking up from WhiteHall, and it would be unfair (and impractical) to give one person a monopoly of all photographs of Nelson's Column.

Against this background, many commentators would have expected that the idea of a black and white photograph with a red bus travelling across Westminster Bridge with the Houses of Parliament and Big Ben 
in the background not to be protected by copyright. As discussed above, although Judge Birss conceded it was a difficult case to decide, he did not reach this conclusion. One academic, Prof Jeremy Phillips, has suggested that the case could represent a worrying development for photographers: 'the photographer who recreates the effect of another's photograph of a public scene or monument is now a copyright infringer, and that there may now be a notion of copyright in an idea, a lay-out or a scheme for such a photograph'. That is, that the decision now blurs what is known as the idea/expression dichotomy in copyright law.

At the time of writing, there was no indication of whether or not NET would appeal the decision to the Court of Appeal. It also worth noting that the decision of Judge Birss is not binding on the High Court (the Patents County Court being restricted to financial claims of less than $£ 500,000$ in intellectual property cases).

Dr Catherine Lee, Solicitor, Osborne Clarke Thames Valley catherine.lee@osborneclarke.com

\section{ASA's harsh verdict on Mercedes Benz 'promotion from hell'}

\section{Stephen Groom}

Journal of Direct, Data and Digital Marketing Practice (2012) 13, 375-378. doi:10.1057/dddmp.2012.8

Topic: Promotion marketing

Who: Mercedes Benz (United Kingdom) Ltd (Mercedes Benz) and the Advertising Standards Authority (ASA)

Where: United Kingdom

When: January 2012

Law stated as at: 1 February 2012

\section{What happened}

The Advertising Standards Authority investigated a complaint by one of the ten finalists (the 'Complainant') in a 'Win a New Vito' competition organized by Mercedes Benz (the 'Competition').

Contestants were invited to submit their own video, written submission or photograph with a caption that demonstrated why they deserved to win a new Mercedes Benz Vito. After the entry closing date, a judging panel would draw up a shortlist of ten entries. These would go online for a month's public voting to decide the Vito winner.

The Complainant questioned whether the competition had been administered fairly, because the rules had been allegedly altered while the competition was in progress. 